\title{
PlaceMaking Approachment to Accomplish Social Sustainability
}

\author{
By Elif KUTAY KARACOR ${ }^{1}$
}

\begin{abstract}
Together with migration and rapid population growth, social relations of the city inhabitants began to deteriorate. Together with this, individualization and isolation of people which leads to social problems have been debated in the scientific literature from the 1960s. In this context, the ensuring of social cohesion has become increasingly important developing by public spaces and place making idea which include communitybased participation approach. However, placemaking idea is criticized because of being elitist, not to provide social equity and caused the gentrification by different views. The aim of this study is introduce that how placemaking idea has been evaluated which is developed by Jane Jacobs' "eyes on the street" concept and become related to social sustainability until now. As a research method, various case studies have been observed and literature review has been conducted. Result of the analysis, process and application differences of placemaking approaches have been examined. Thus, how placemaking approach to be effective in different places on social sustainability was discussed, hence the positive and negative aspects were revealed as well. Obtained results of this study are expected that contribute to the design and planning principles of cities to create engaged community.
\end{abstract}

Keywords: Placemaking, community, social sustainability

\section{Introduction}

Together with extreme population growth and migration, some social issues such as alienation, violence and insecurity have caused to concern of how to ensure social sustainability in today's urban areas. Therefore, various approaches that will contribute to human relations and will increase of life quality perception by developing of social cohesion are presented. As accepted one of these approaches, placemaking emerged in the 1960s and its spatial applications are grown up in different scales of the places. On the one hand, while it's been supported (Burton et al., 2010; Shibley, 2003), on the other hand it has some critics (Mehta, 2012; Bedoya, 2012; Zukin et al., 2009). In this study, placemaking experiences of two different neighborhoods from Istanbul and New York cities where are facing with globalization have been evaluated and then the causes and consequences of the placemaking process have been discussed. Importance of the study is due to reveal of the experiences of cities which are under the pressure of globalization and capital. 
The 1960s when the placemaking concept appeared first, reactions of people revealed against the existing order all around the world. Together with gaining importance of the individual rights and of the freedoms, people started to protest of social issues on urban areas such as unhealthy living conditions, social inequity and criminal environment which have been handled by comprehensive urban planning until that time.

Jane Jacobs (1961) is one of the urban thinkers opposed to urban interventions which were implemented by governers and asserted that streets of the cities should be experienced by their citizens. She built a connection between city street and living organisms. So, she defined streets as "lifeblood" with revitalizing functions of the city. In this context, she suggests that street oriented public life contribute to the safety of cities and put forward that little shops which are located with residential areas could provide "eyes on the street". According to Jacobs (1961), experiencing of urban streets leads to social cohesion and sense of belonging. After the noticing of Jacobs (1961), spatial approaches which are sensitive to social relationships of the communities began to appreciated.

In addition, William Whyte was interested with social structure of urban life in the 1960s and opposed to top-down planning. According to Whyte (1980), social life of public space contributes to the quality of life of individuals and society. So, he considered that creating physical places that facilitate civic engagement and community interaction is moral responsibility and after the learnt what people want in public spaces, livable communities could be shaped by creating places (PPS, 2014a: Whyte, 1980).

The views that have been emerged to develop public life in 1960s, have been supported with some approaches which were developed by Norberg-Schulz (1979) and Relph (1976) in 1970s such as spaces can be meaningful with by having spirit and would turn into places. Norberg-Schulz (1979) has mentioned about residential areas lost own character, especially after the World War II and he suggests that modern environment where isn't human oriented doesn't offer any surprises and discoveries.

Relph (1976) assert that public places can achieve their publicity and distinctiveness through high imagebility. It could be found similar to views of Relph (1976) and Lynch (1960) about imagebility of places. Lynch (1960) has asserted that the city's image will improve the physical environment and its citizens will have a communal image over the time. In this sense, the physical structure of the space has been interpreted by social structure. Together with political and social changes that were seen all over the world and beginning of the reactions to modern planning, the presence of spaces which relieve the soul of human and developing of social relationships have gained prominence. Since this period, placemaking approach has gained importance and as asserted by Aravot (2002) "urban design was directed towards placemaking". On the other hand, PPS (2014a) suggests that placemaking isn't design driven and project focused, but it emphasizes to its community driven aspect.

However, it can not be ignored that urban design will improve the perception of quality of life and contribute to placemaking while considering it shapes our environment with aesthetical arrangements which facilitate social interaction. New Urbanism movement which emerges as a solution to problems of today's cities, integrates urban design and placemaking. It supports placemaking approach, because of placemaking cares about human scale and focus on sustainability and life quality. 


\section{Importance of Placemaking}

There are some views which suggest that placemaking would contribute to social and economic developments by improving physical environment. Burton et al. (2010), emphasize that social problems are related to physical environmental quality and suggest that they can be solved by developing of physical environment. So, they assert that placemaking is needed in especially socially and economically deteriorated areas.

Place based responses to social problems emerge from the policies that the physical environment can positively influence wellbeing and quality of life. Increase of social problems in urban areas led to rising of crime rates and anti-social behavior associated with reduction of perceived safety. These are generally engaged with social and spatial disparities between rich residents in affluent with high-quality areas and poor residents in generally poorer quality of housing and environments in less affluent areas. It is supposed that fear of crime tends to be higher in a poorer quality environment with litter, graffiti and anti-social behavior. So, placemaking is needed in especially deteriorated areas in case of socially and economically (Burton et al, 2010).

Placemaking view claims that environmental quality can be improved by new economical opportunities with small shops and street vendors. So, safety and security can be provided by vibrant street life and it contributes to development of social sustainability. The deficiency of public spaces would make worsen relationships between people. If people loss the chance of meeting with each other, they can't develop common values such as tolerance, esteem and confidence which contribute to social networks.

Shibley (2003) refers not to environmental quality, but quality of relationships between people and places and suggests that placemaking is not only physical construction and maintenance of places. Also, he recommends that good design has to be sensitive about human relationships for perfect placemaking.

Therefore, loss of identity of urban areas with globalization, inability of integration between new owners of the cities and their inhabitants and increase of democratic demands lead to question of how to ensure of social sustainability. Places are getting important where different social groups' can develop mutual meanings and can feel belongings. Increase of shared public spaces challenge to social problems by contribute to belonging and sense of place. Thus, they help to establish a link between people and places where they live in. The success of placemaking about social issues can be connected with that it is against to top-down planning and considers of individual differences by human behavior centered.

\section{Placemaking Process}

Each urban intervention is unique because of the having different social dynamics, so placemaking cannot be "operationalized" with specific design rules to be applied everywhere (Shibley, 2003). That's why every placemaking should reflect own character of space and should consider needs and opportunities both of the society and location. The deficiencies and problems resulting from the placemaking process may provide a guidance for the next placemaking studies. 
When considering of each place and community is unique, long process of the placemaking could be perceived as reasonable. One of the most distinguishing features of placemaking approach is not only a planning or design; beyond all of them the action comprises the process by itself. Because of placemaking has long process which includes future expectations, it should consider that needs and expectations of not only today's people, but also next generations.

The great places should include at least 10 reasons to be there or 10 things to do. These could include a place to sit, playgrounds to enjoy, art to touch, music to hear, food to eat, history to experience, and people to meet, etc,. It can be preferred that all those different activities which are held on the places are unique and interesting to keep people comes back (PPS, 2014b). This idea of placemaking overlaps with mix use suggestion of new urbanism. The richness of different activities in the area could increase to the economic viability and the number of visitors as well. As defined by (Lanham, 2007), placemaking process generates economic growth and promotes cultural tourism with capital investment.

It is important that sharing of the benefits which will arise as a result of the economic growth and vitality by whom. For this reason, participation of the community and ensuring of the benefits should be essential part of the process.

Besides, it is expected from placemaking process encourage to democratic participation. Together with participatory placemaking process, environmental and social awareness is increased. So, people will maintain and adopt the places which are improved by common decisions. The increase of sensitivity to spaces from different scales where people live in could contribute to voluntarism about social issues and develop to nongovernmental organizations. Additionally, social networks could be strengthened providing by participation of different social groups with flexible design features. Lepofsky and Fraser (2003) emphasize that participation is one of the integral part of placemaking and considered it as both in the production of meaning and in the means of production of a space.

Because of its bottom-up process, placemaking should make disadvantaged groups' voices heard and connect them each other and with society. It draws on the assets and skills of a community rather than professional expert's decisions, so individual differences could be regarded.

\section{Critiques of Placemaking}

As mentioned above, there are different reasons come up with to support placemaking idea. Especially, experienced and faced social problems such as unsafety, crime rates, deteriorated buildings and spaces, etc. might lead to placemaking construction justifiably in cities. On the other hand, some authors criticize placemaking idea because of not to solve social problems, only make them more complicated. Saitta (2013) examined whether placemaking is elitist or not and asserted that placemaking works for only specific social groups such as high income and cultural creators. Mehta (2012) is asking in his article who are the beneficiaries of investments, activities and strategies of placemaking? And how is creative placemaking benefit to low income 
communities and communities of color? And he asserts that the beneficiaries of revitalizing local economy are out of the community.

Furthermore, Bedoya (2012) considers placemaking practices and discourses as blind spot to the social and racial injustices in society and claims that placemakers are lack of awareness about the politics of belonging and dis-belonging which are related to sense of place that is defined as one of the goals of placemaking (Markusen and Gadwa, 2010). Increase of property values after the placemaking process lead to replacing of the places. Thus, relationships are broken which have been developed between inhabitants and places and sense of place is disappeared. In addition, newcomers how much feel themselves as "belonging" to the area is the subject of discussion.

Zukin et al. (2009) noticed that urban revitalization which is supported by placemakers may benefit certain residents while deepening economic and social polarization and places of low- and middle-income neighborhoods are under the risk. It enhances the quality of life of the new urban middle class, including the new black middle class, while making the poor of every ethnic group feel insecure.

Because of the placemaking supports urban revitalization and only has benefits to high income groups, leads to raise of concern that it may cause to gentrification especially in the historical areas.

\section{Case Studies}

\section{Akaretler}

Akaretler row houses is located on Besiktas district of Istanbul and was built by Sultan Abdulaziz for the accommodation of the high ranking officers of Dolmabahce Palace. After the collapsed of Ottoman Empire, Akaretler district was abandoned and became depressed. It was leased by private company in 1987 for 49 years and was operated by public-private partnership. As a part of this operation, it was restored in 2008 (Akaretler, n.d.) (Figure 1).
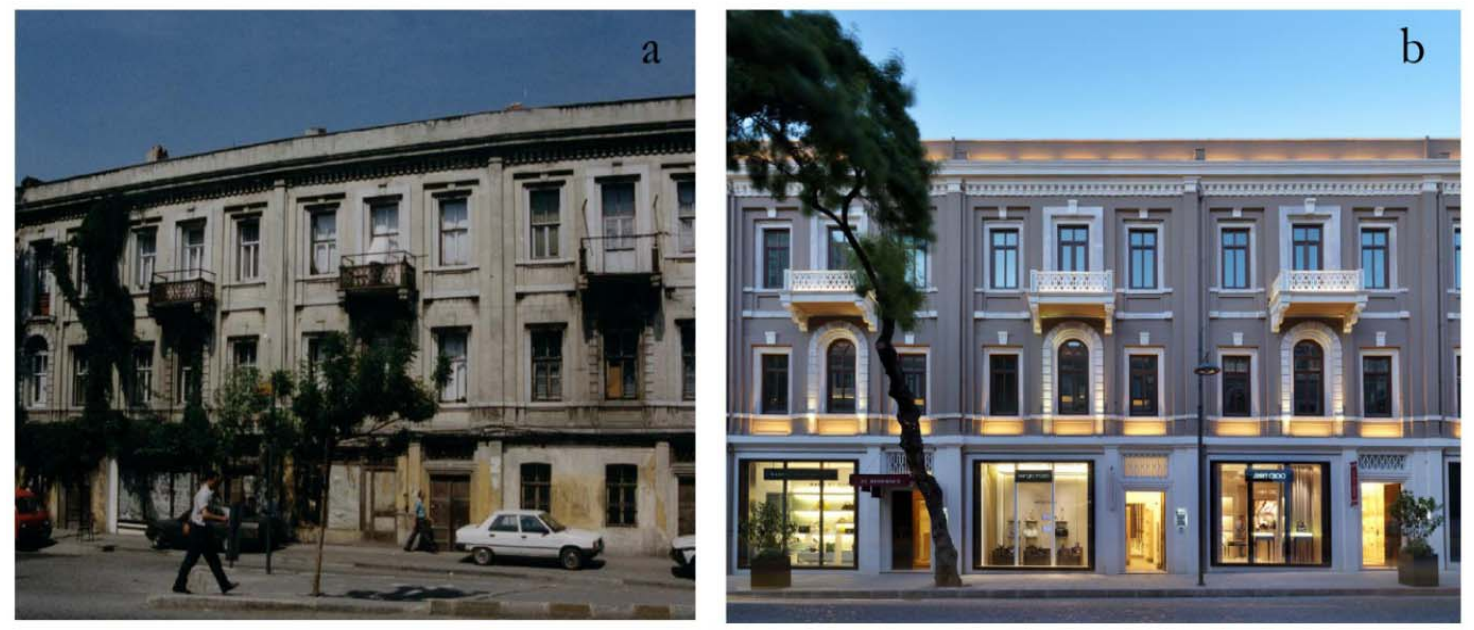

Figure 1. Before (a) and after (b) the placemaking and restoration project (Surmegoz, 2010). 
After the completion of restoration, luxury boutique shops, art galleries, cafes, residences and one of luxury chain hotel was located in Akaretler. Together with the development of art and commercial activity, street life has been revitalized and various functions have been created for the development of social relationships. As a result of has remarkable building facades, Akaretler has been drawn attention by the tourists and it has high potential accessibility and gives priority to pedestrian movements for visitors. Because of it is being closed to other landmarks such as The Naval Museum, Sinan Pasha Mosque and Barbaros Hayreddin Pasha Tomb which are located in Besiktas district and being connected to different locations by public transportations (buses, minibuses, boats, etc.) around the city, it increase the attractiveness of Akaretler. According to (Surmegoz, 2010), after the replacing of bars, restaurants and cafes which contribute to night use of Akaretler, crime rates decreased and life quality was improved.

On the other hand, this placemaking implementation is controversial in case of its performance. Surmegoz (2010) noticed that both rent values and sales values of properties increased in turn $200 \%$ and $90 \%$ around Akaretler neighborhood. According to TRER (2012), Besiktas was the only district to witness a slight increase in rent values during the first three quarters of 2012. This situation was associated with luxury and boutique style office buildings as a result of the introduced by Akaretler placemaking projects. Together with high demand to area, rent values continue to rise.

Revitalizing local economies, sense of place and belonging issues which are described among the goals of placemaking by (Mehta, 2012; Markusen and Gadwa, 2010) were insufficient and high-income groups moved into the area. Besides, boutique style office buildings are replaced by luxury chain stores and don't make any contribution directly to local economy. Even if participatory process and community driven are accepted as the essential priniples of placemaking, community driven side was disregarded and expectations and needs of local community weren't considered while producing decisions.

\section{Greenwich}

SOHO district where includes Greenwich neighborhood is one of the first free black settlement of Manhattan island. It was retained by black population for over two hundred years, until the middle of 19th century when the areas changed from residential to commercial use. By the middle of 19th century, replaced with cast iron architecture, commercial companies began to open. After the civil war, manufacturers moved into area. At the end of 19th century, these manufacturers moved out to south of the city and the quality of area declined. In 1960s creative industries discovered these empty stylish architectural buildings and the character of neighborhood changed (Lindsay et al., 1973). During the 1980s, art galleries in turn were replaced by individually owned boutiques and were replaced by chain stores in 1990s (Zukin and Braslow, 2011). It is not surprising that the reason of why the people prefer to live or visit the area where has historical buildings, attractive storefronts and vibrant street life. Car parking regulations have been implemented because of it has narrow street, and car traffic has been slow down for the pedestrians. The accessibility of the neighborhood is provided by subway lanes and bus routes. Washington Square Park and High Line Park which are important recreational open spaces are located within walking district to this area. Together with Bleecker Street 
that one of the most attractive street of Greenwich, they create popular network for people' strolling and having fun. The wideness of sidewalks gives a chance to people for social interaction. Some cafes take an advantage of this opportunity to draw attention of people and serve as open air cafes. Retail establishment with residences above contribute mix use urban development and helps to increase of safety with all day use (Figure 2). So, PPS (2014c) asserts that Bleecker Street of Greenwich neighborhood is one of the greatest places in the world.
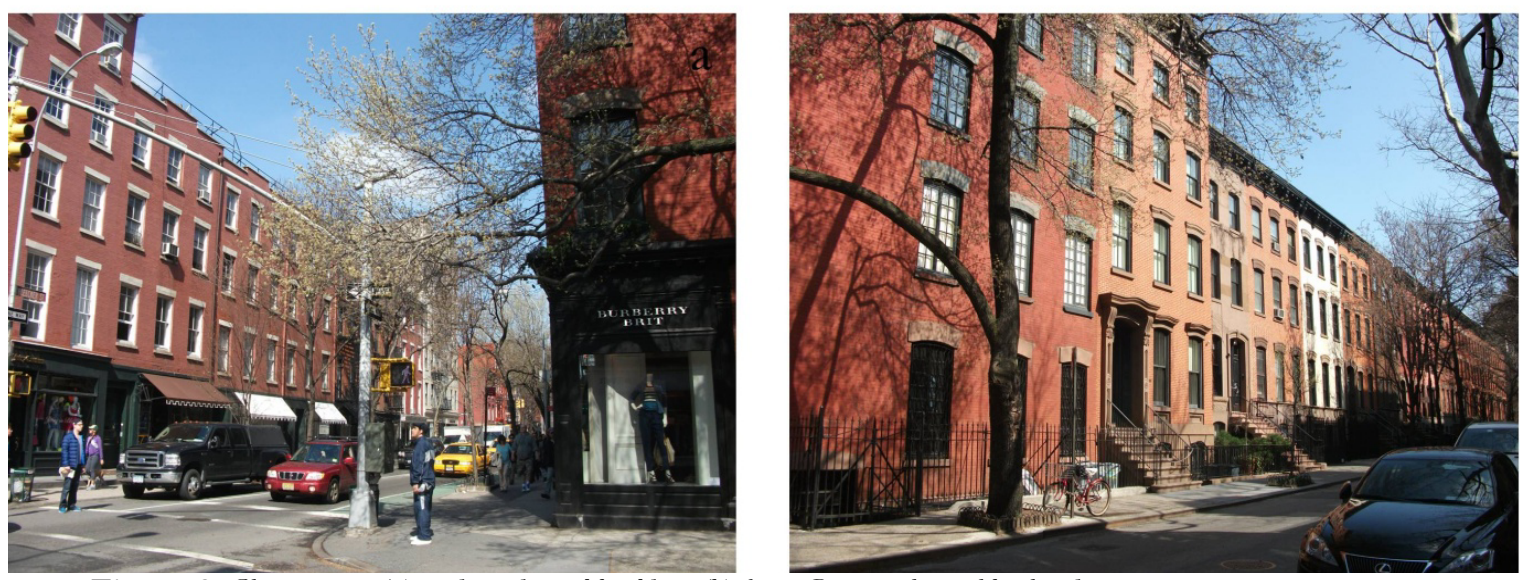

Figure 2. Chain stores (a) and residential buildings(b) from Greenwich neighborhood

Most of placemaking activities and events are held by The Greenwich Village Society for Historic Preservation (GVSHP). This non-profit organization was founded in 1980 to preserve the architectural heritage and cultural history of Greenwich Village and its vicinity. In scope of its program, public lectures, tours, exhibitions, etc. are organized and preservation projects are developed (GVSHP, 2014). It is very important that participation of non-governmental organizations (NGO) into placemaking process to protect disadvantaged groups and to help creating equal opportunities for everyone. Having an NGO of the neighborhood which is regarded by the city government and discussing of the issues via workshops could increase the chance of success and contribute to development of social relationships.

However, Zukin and Braslow (2011) noticed that Greenwich Village faced with unanticipated consequences of unplanned areas where artists work and live higher housing prices, so displacement and gentrification has been revealed. According to NYC Department of Finance Property Assessment Roll Archives, residential property values in Greenwich village increased \%35,2 from 2008 to 2012 (NYC, 2014). Especially after the 1990s chain stores bring high-income groups into the area and this situation affected middle-income inhabitants negatively due to increase of property values. So, it's been questioned how can people share public spaces and experience together while they are from different income levels? 


\section{Conclusion}

The cases of this study show that placemaking process has positive impacts such as increased life quality and decreased crime rates on the big cities. This situation supports the view of physical environmental quality helps to solve social issues. However, placemaking led to increase of property values, and so it caused to change of the users' profile and community members of the places. Moved out of the area of low and middle-income groups would cause to segregation of the communities. Replacing of the people according to income levels would decrease sense of places. For this reason, providing of participation into the placemaking process is very important. Besides, rights of the disadvantaged groups should be protected by legal regulations in this process. Especially in historical areas, using of placemaking process as a tool to increase of property taxes would cause to social inequity; because of most of inhabitants are from low or middle income groups. Consequently, urban designers and planners should be sensitive about social dynamics and perceive to contribute them as a moral responsibility.

\section{References}

Akaretler. (n.d.). In Akaretler Istanbul. Retrieved May 28, 2014, from http://www.akaretler.com.tr/

Aravot, I. (2002). Back to phenomenological placemaking. Journal of Urban Design, 7(2), 201-212.

Bedoya, R. (2012). Creative Placemaking and the Politics of Belonging and Dis-Belonging. http://www.artsinachangingamerica.net/2012/09/01/creative-placemaking-and-the-politics-ofbelonging-and-dis-belonging/

Burton, M., Dempsey, N., Stefan, K. (2010). 'Place-keeping' in the cultural landscape: the role of long-term maintenance and management. Proceedings of 27th ECLAS Conference in Istanbul 29 September-2 October 2010.

GVSHP. (2014). In Greenwich village society for historic preservation. Retrieved May 25, 2014, from http://www.gvshp.org/_gvshp/index.htm

Jacobs, J. (1961). The death and life great American cities. New York:Vintage Books.

Lanham, K.F. (2007). Planning as placemaking: tensions of scale, culture and identity. Virginia Polytechnic Institute and State University School of Public and International Affairs College of Architecture and Urban Studies Master of Urban and Regional Planning Major Paper.

Lepofsky, J., Fraser, J.C. (2003). Building community citizens: Claiming the right to place-making in the city. Urban Studies, 40(1), 127-142.

Lindsay, J.V., Clurman, R.M., Goldstone, H.H. (1973). Sobo-cast iron historic district designation report by city of New York.

Lynch, K. (1960). The image of the city. Boston: Massachusetts Institute of Technology.

Mehta, N. (2012). The question all creative placemakers should ask. Retrieved from http://nextcity.org/daily/entry/the-question-all-creative-placemakers-should-ask

Markusen, A., Gadwa, A. (2010). Creative placemaking - executive summary. A white paper for The Mayors' Institute on City Design, a leadership initiative on the National Endowment for the Arts in partnership with the United States Conference of Mayors and American Architectural Foundation. NEA 2010. 77 pp. Washington:

Norberg-Schulz, C. (1979). Genius loci-towards a phenomenology of architecture. New York: Rizzoli.

NYC (2014). In The official website of the city of New York. Retrieved June 20, 2014, from http://www.nyc.gov/html/dof/html/property/assessment.shtml\#roll

PPS. (2014a). In Project for public space - William H. Whyte. Retrieved May 13, 2014, from http://www.pps.org/reference/wwhyte/

PPS. (2014b). In Project for public space - the power of ten. Retrieved May 24, 2014, from http://www.pps.org/reference/the-power-of-10/ 
PPS. (2014c). In Project for public space -Bleecker Street. Retrieved May 25, 2014, from http://www.pps.org/great_public_spaces/one?public_place_id=104

Relph, E. (1976). Place and placelessness. London:Pion

Saitta, D. (2013). Is 'Sustainable' Urban Placemaking Elitist? Intercultural Urbanism Interdisciplinary Perspectives on Urban Culture, Space, Architecture, and Design. http://www.interculturalurbanism.com/?p=3126

Shibley, R.G. (2003). Case studies in urban design. In D. Watson et al. (Eds.), Time-saver standards for urban design. New York:The McGraw-Hill.

Surmegoz, K. (2010). Urban design as an instrument of re-evaluation at historical environments; Besiktas Akaretler Rowhouses. Mimar Sinan Fine Arts University Graduate School of Science Master Thesis (in Turkish).

TRER. (2012). Turkey Real Estate Review 2012 second half report. Retrieved May 24, 2014, from http://www.colliers.com/ /media/files/emea/turkey/research/2012-2-turkey-review-revised.pdf

Whyte, W.H. (1980). "Introduction", "the life of plazas", "sitting space", and "sun, wind, trees and water" from the social life of small urban spaces. In M. Larice and E. Macdonald (Eds.), The urban design reader. Oxon:Routledge.

Zukin, S., Trujillo, V., Frase, P., Jackson, D., Recuber, T., Walker, A. (2009). New retail capital and neighborhood change: boutiques and gentrification in New York City. City \& Community, 8 (1),4764.

Zukin, S., Braslow, L. (2011). The life cycle of New York's creative districts: Reflections on the unanticipated consequences of unplanned cultural zones. City, Culture and Society, 2 , 131-140. 
